\title{
Observation on Virtual Reality - based Training System on Numerical Control Technology Training
}

\author{
Yemane Zemicheal \\ Mechanical Manufacturing and Automation \\ Tianjin University of Technology and Education, \\ Tianjin, China
}

\author{
Qi Houjun \\ Mechanical Manufacturing and Automation \\ Tianjin University of Technology and Education, \\ Tianjin, China
}

\begin{abstract}
This paper focuses on the implication of virtual reality based training system for advanced machining technology training. It is part of a major study that examined the construction of a curriculum for High speed machining Technology specialty on the engineering technology field. The overall aim of the study was to contribute to the improvement of the High speed machining Technology curriculum development and engineering technology students' learning by utilizing both theoretical and empirical inquiry. Virtual reality is a technology which allows a user (trainee) to interact with a computersimulated environment, whether that environment is a simulation of the real world or an imaginary world. Virtual Reality (VR) sometimes called Virtual Environments (VE) is a new tool in education and training which helps students see and experience the real process and operation in a simulated graphics computer. Apart from being an interesting educational experience, it also saves institutional associated costs in terms of human injury and equipment failure on an excursion. The paper emphasizes the idea that the virtual reality based training system is used to develop and enhance the effectiveness of talent cultivation on advanced manufacturing technologies. Some of the issues related to the concept of Virtual Reality, use of virtual reality on technological education, and reflections on virtual reality based training strategy are also addressed.
\end{abstract}

Keywords - Virtual Reality; Manufacturing Simulation; CNC; Virtual reality based training system; Virtual reality; engineering education; High speed machining technology

\section{INTRODUCTION}

The concept of Virtual Reality (VR) refers to a computer generated virtual Environment that may be moved through and manipulated by a user in real time. A virtual environment may be displayed on a computer monitor or projection screen it can be equipped with special hardware such as Head Mounted Display (HMD), Data Glove and special glasses [1]. According to the Collins dictionary "Virtual reality is an environment which is produced by a computer and seems very like reality to the person experiencing it". "Virtual Reality is a way for human to visualize, manipulate and interact with computers and extremely complex data" (Austakalnis \& Blatner 1992) [2]. It is considered to have begun in the 1950's but it came to the public's attention in the late 1980's and 1990's [1].

Virtual Reality Technologies are a recent innovation and issue in the Technological world industry, although virtual reality technologies are not restricted to specialized areas of disciplines anymore like computer games, aerospace industry; at present, these Virtual technologies are used in many areas of disciplines, including medicine, geography, education/Training (like CNC machining Training), advertising, etc [3]. Virtual reality Technology allows a user to interact with a computer-simulated environment, whether that environment is a simulation of the real world or an imaginary world. It is an artificial environment that is created with software and presented to the user in such a way that the user suspends belief and accepts it as a real environment [4]. Virtual reality can replace and simulate the real world with its artificial computer-generated environment so the user can interact with it as if he is actually doing it [2]. With the Advancement of $\mathrm{CNC}$ machines in the manufacturing industry, recently in the field of $\mathrm{CNC}$ machining Virtual Reality applications are able to virtually display machining processes. This technique is more advantageous for Trainees (Students) to learn how to set up machines and use CNC machines safely without any damage, risk, waste or breaks [5].

This paper discusses the types of Virtual reality that have been used for numerical control Technology Training (mostly numerical control milling machine) but does not attempt to cover all Virtual Reality technologies mainly because this virtual technology is developing rapidly and new methods are continually emerging everyday [6].

\section{USE OF VR IN TECHNOLOGICAL EDUCATION AND TRAINING}

In the competitive world designers, engineers and manufacturers are constantly innovating new manufacturing and training delivery strategies in order to reduce product development cost, time and personnel accidents [7] Nowadays it becomes impossible for new users (Trainees and new employees) to have on the real machine training experience on high speed CNC machines because of both the risks from accidents and damaging tools, as well as the impossibility of having sensorial feedback using the trial and error method. The paradox is that, because of work activity dematerialization, virtual reality can provide more tangible and direct contacts with processes like real situations. Moreover, additional cues and data can be added to facilitate the realization of an activity or to support learning/training [8]. 
To become more efficient, avoid wasting time and material; trainees need to upgrade their skill and knowledge through new methods and technology. Well-trained and knowledgeable trainees can improve their work efficiency and prevent themselves from getting hurt in a hazardous environment. In the advanced technological education field practical training is critical to upgrade their skills, prevent damages to equipments and tools thus reducing operating cost and can avoid human fatality. Safety is another important factor that can be improved by providing technological supported training to students. Several educational resources can be used in training including printed materials, videos and computers. Virtual reality-based training strategy is an advanced method of training and one of the latest technologies being utilized today. Virtual reality technology provides more interactive user interface and has been proven to be an efficient training tools. Over the past few years, a number of Virtual reality-based training systems have been developed. Areas of research and development in virtual reality based training include training for military, aviation, advanced manufacturing, medicine, mining industry and many other areas. [2]

Virtual reality based Education and training systems are advanced technology assisted training systems using Virtual Reality technology. In comparison with traditional education and training approaches, these methods would allow trainees to properly operate more advanced equipments before the actual operation is performed. The important abilities, knowledge and skills acquired through the virtual reality training system enable trainees to become more effective and familiar with the real-world operation, the experience gained is directly transferable to the real world. More importantly, the virtual reality training approach can provide higher degree of freedom for operation and the results of improper operation can be simulated without incurring the associated costs in terms of human injury and equipment failure [9].

In addition according to the literatures and our observation in Tianjin University of Technology and Education, China, Virtual Reality is motivating, and students have a positive attitude towards using the Virtual Reality technology in their training process. Furthermore, virtual reality grabs and holds students' attention, probably because it is exciting and challenging to interact, create, and manipulate objects in a virtual environment, but also because virtual reality adds precision, and permits visualizing objects and processes that are impossible to show in a real environment [3]. Virtual reality can more accurately illustrate some features, processes, and so forth than by other means. Virtual reality allows extreme close-up examination of an object. Virtual reality gives the opportunity for insights based on new perspectives. Looking at the model of an object and process from the inside or the top or bottom shows areas never seen before. Virtual reality allows examination of an object from a distance, showing the whole rather than a part [10].

Nowadays virtual reality technologies are used for conducting NC machine trainings before the real machine training by a number of Technical Universities and Technical Training Centers as well, because they offer lower training costs than the real NC machining training and they are much safer (see Fig. 1) [11].

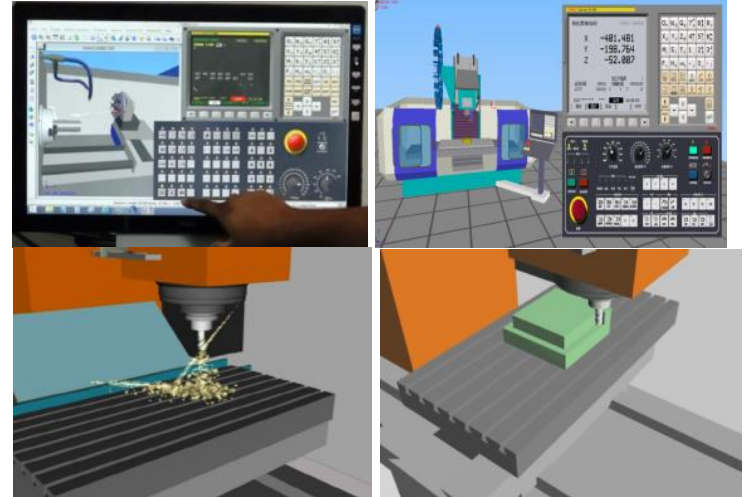

Fig.1 Graphical pictures of the Virtual reality CNC machine Model simulators

Also, limited availability of training facilities (e.g. CNC machines) and personnel resources can make it difficult to train large numbers of trainees for any given machine. To overcome these problems and difficulties, it is recommended to implement virtual reality-based training for $\mathrm{CNC}$ machine operations. More importantly, it is safer and more economical to practice as a beginner on a virtual $\mathrm{CNC}$ machines than on the real CNC machine. [12]

One of the main reasons why virtual reality has been used for educational and training purposes is the support of high interactivity and the abilities to present a virtual environment that resembles the real world (see fig. 2). With this technology, trainees can explore and manipulate threedimensional interactive environment [6].Virtual reality technology allows a trainee to train by doing; it can provide experience with new technologies through actual use [10].

Pantelidis (1995) cited in [10] pointed out the following reasons to use virtual reality in education and Training: I.) Virtual reality technology provides new forms and methods of visualization. It provides an alternate method for demonstration of machining processes. In some situations, VR can more accurately illustrate some features, processes, and so forth than by other means, allowing extreme close-up examination of an object, observation from a great distance, and observation and examination of areas and events unavailable by other means. II.) Virtual reality motivates students' interest. It requires close interaction and encourages active participation rather than passivity. III.) Virtual reality allows the learner to proceed through an experience during a broad time period not fixed by a regular class schedule, at their own pace.

Generally implementing Virtual reality technology in the education and training system provides more interactive visualization and interaction experience. Sometimes it is difficult to implement the new advanced technology due to the high initial investment cost of equipment but there are many possibilities to access virtual reality technology in different forms. In virtual reality technology experiments can be carried out for as long as the user/trainee wishes; all students can be able to realize their own experiments and learn the machine and process better [13].

\section{REFLECTIONS ON VIRTUAL REALITY BASED TRAINING STRATEGY}

Virtual reality is emerging as a powerful technological education tool in the manufacturing engineering education, 
especially $\mathrm{CNC}$ machining training. The main objective of the engineering technology program ( $\mathrm{CNC}$ machining training) is to prepare students with the necessary skills to be successful in the engineering technology field, to improve the qualifications and competences of the trainees, which are directly related to the required qualifications. Normally the interaction with the virtual reality technology (a lower level of immersive Virtual reality) has involved the use of machine control unit to input information and the use of a visual display unit to receive output from the system. With the advancement of Virtual Reality technology systems, various interaction methods have been developed that allow the user to step into simulated, or virtual, environments which is achieved by immersing the user in the artificial environment [14].

The following are some of the points made during our observation;

$>$ The training was attractive as all the trainees were interested and none left their sessions.

$>$ The trainees were practicing the technology attentively.

$>$ The session was student center; the instructor was acting like facilitator to explain some points raised by the trainees.

$>$ The trainees were eager for the next session. It makes them more motivated and committed.

$>$ The teacher can enhance the trainees understanding on a certain situation by making intentional errors in that particular situation.

In this regard, taking into consideration the quick evolution of advanced technologies in the industrial world, the use of virtual reality technology is more feasible and affordable for educational institutions and students than ever before especially for the high speed machining Technology program curriculum, so it is relevant to understand what are the plusses and minuses of using these technologies in educational environments. On the other hand, there are some difficulties like the resistance of traditional learning environments to integrate educational innovations, the opposition of teachers to adopt new technologies out of their comfort zone, and the costs involved to implement these technologies [3]

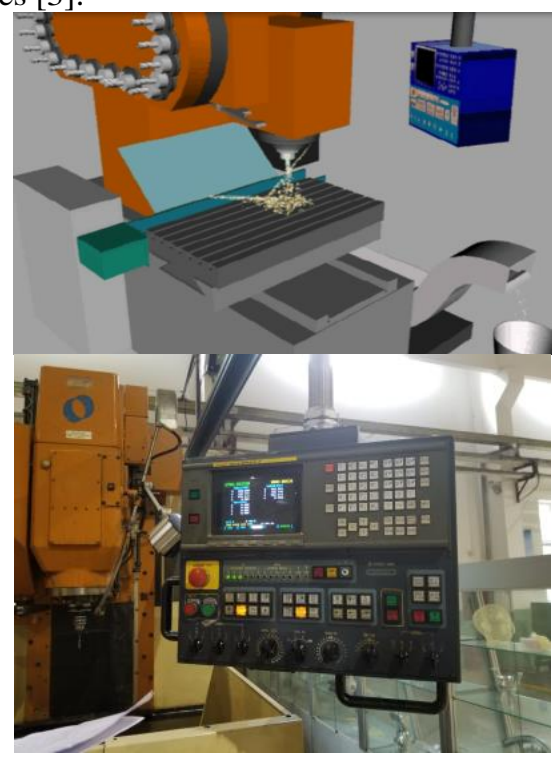

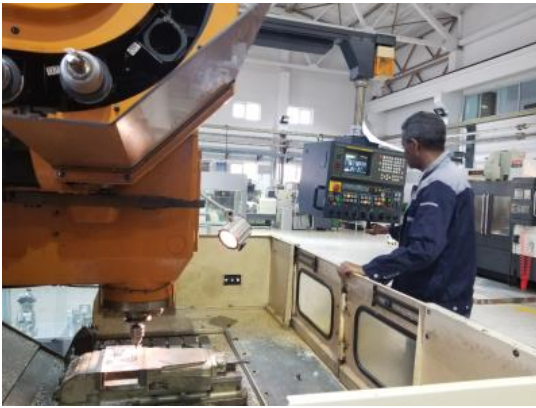

Fig. 2 The simulated image of the machine and the real NC machining center.

\section{CONCLUSION}

In this paper, our observation on virtual reality-based training system on numerical control technology training is described. Effectiveness of educational training process in educational institutions can be improved by introducing new modes of training and new technologies such as technological simulations using virtual reality technologies. Virtual reality technologies are efficient tools for education and training activities. Like flight simulators are fundamental for airplane flight training, the main idea of the virtual reality technology is suitable for the training reform of numerical control courses under the high speed machining technology program. It can allow trainees to address and simulate the real NC machine operations and functioning for the first time after gaining a required knowledge.

In addition it is better to introduce the upgraded virtual reality technology (i.e fully immersive with full software and hardware resources) to further strengthen the practice of high speed machining technology curriculum.

\section{ACKNOWLEDGMENT}

The authors would like to acknowledge that some instructors at Tianjin University of Technology and education were involved in developing of the high speed machining technology program curriculum. The authors wish to thank Mr. Wang jincheng for his invaluable support to this work.

\section{REFERENCES}

[1] Mandal, S. (2013). Brief introduction of virtual reality \& its challenges. International Journal of Scientific \& Engineering Research, 4(4), 304-309.

[2] Hamouda, A. M. S., Al-Khalifa, K. N., \& Arshad, H ENHANCING ENGINEERING EDUCATION WITH VIRTUAL TECHNOLOGY: The Case of Industrial Engineering Curriculum.

[3] Martín-Gutiérrez, J., Mora, C. E., Añorbe-Díaz, B., \& GonzálezMarrero, A. (2017). Virtual technologies trends in education. EURASIA Journal of Mathematics Science and Technology Education, 13(2), 469-486.

[4] Ramaprabha, T., \& Sathik, M. (2012). The efficiency enhancement in non immersive virtual reality system by haptic devices. International journal of advanced research in computer science and software engineering, 2(3), 113-117.

[5] Valvo, E. L., Licari, R., \& Adornetto, A. (2012). CNC milling machine simulation in engineering education. iJOE, 8(2), 33.

[6] Lee, E. A. L., \& Wong, K. W. (2008). A review of using virtual reality for learning. In Transactions on edutainment I (pp. 231241). Springer, Berlin, Heidelberg.

[7] Ertekin, Y., Husanu, I. N. C., Belu, R. G., \& Zhou, J. G. (2013, June). Virtual 3-d laboratory for cnc machining and automation 
curriculum. In 2013 ASEE Annual Conference \& Exposition (pp. 23-1357).

[8] Mellet-d'Huart, D. (2009). Virtual reality for training and lifelong learning. Themes in science and technology education, 2(1-2), 185-224.

[9] Lin, F., Ye, L., Duffy, V. G., \& Su, C. J. (2002). Developing virtual environments for industrial training. Information Sciences, 140(1-2), 153-170.

[10] Pantelidis, V. S. (2010). Reasons to use virtual reality in education and training courses and a model to determine when to use virtual reality. Themes in Science and Technology Education, 2(1-2), 59-70.

[11] Mazuryk, T., \& Gervautz, M. (1996). Virtual reality-history, applications, technology and future.

[12] Lin, F., Hon, C. L., \& Su, C. J. (1996). A virtual reality-based training system for $\mathrm{CNC}$ milling machine operations. Annual Journal of the IIE HK.
[13] Hee Lee, J., \& Shvetsova, O. A. (2019). The Impact of VR Application on Student's Competency Development: A Comparative Study of Regular and VR Engineering Classes with Similar Competency Scopes. Sustainability, 11(8), 2221.

[14] Costello, P. J. (1997). Health and safety issues associated with virtual reality: a review of current literature (pp. 1-23). Loughborough, UK: Advisory Group on Computer Graphics.

[15] Pantelidis, V. S. (1995). Reasons to use virtual reality in education. VR in the Schools, 1(1), 9.

[16] Chen, C. J. (2010). Theoretical bases for using virtual reality in education. Themes in Science and Technology Education, 2(1-2), 71-90.

[17] Valvo, E. L., Licari, R., \& Adornetto, A. (2012). CNC milling machine simulation in engineering education. iJOE, 8(2), 33. 